\title{
A perspective of pipejacking works by tunnel boring machines in Hong Kong: part I - development, selection of design, operations and types of techniques
}

\author{
Wilson W S Mok ${ }^{1}$ and Andrew S W Ng ${ }^{2}$ \\ ${ }^{1}$ Independent Trenchless Consultant, Hong Kong, People's Republic of China \\ ${ }^{2}$ Victory Trenchless Engineering Company Limited, Hong Kong, People's Republic of China
}

\begin{abstract}
In this paper, the history of pipejacking works by tunnel boring machines in Hong Kong, their development, selection of design method and tunnel boring machine (TBM), operations, length and alignment of a pipeline, types of techniques to suit different site constraints and ground conditions, and performance of the works are discussed. This paper should be read together with part II, which covers applications, problems encountered, cost and prospects.
\end{abstract}

$\begin{array}{ll}\text { KEYWORDS } & \text { TBM pipejacking; cutterhead; curved alignment; volume-controlled automatic lubrication system; intermediate jacking } \\ & \text { station; long drives } \\ \text { CONTACT } & \text { Wilson W S Mok wilsonwsmok@netvigator.com }\end{array}$

Received 28 March 2021

\section{Introduction}

It is a worldwide trend today to adopt the tunnelling method rather than the open trench method for constructing large pipelines. This is true especially in urban areas where the open trench method causes disruption to traffic and affects the normal operation of existing underground utilities and services. Such public nuisance is intolerable to the community, even for public works construction which will surely result in an improvement to their lives.

Like most major cities, the roads of Hong Kong are underlain by an extensive network of utilities and services. Due to aging or decay leading to leakages and ultimately collapse, as well as rapid population growth, the replacement or continuous installation of new and larger capacity of these features is to be required. Available underground space becomes smaller with time due to occupation by such features. Use of the open trench method is difficult, if not impossible, by virtue of the congested utilities, inconvenience to road users, pedestrians and nearby buildings, and environmental issues such as noise, dust, and muddy water. Deployment of pipejacking methods could generally resolve these problems and ensure the completion of works within the prescribed time frame.

Pipejacking, a type of mini-tunnelling, is the technique of installing pipelines by hydraulic jacking a pipe string, including a tunnelling shield in front, from a jacking pit to a receiving pit. The tunnelling shield either contains electrical and mechanical equipment inside for carrying out the excavation work (called a tunnel boring machine (TBM)) or is used to accommodate workers to carry out the excavation work manually (called a hand-shield or manshield). At the start of a TBM pipejacking operation, the pipe string consists of the tunnelling shield only. Jacking pipes are added one after another to the end of the pipe string as the preceding pipe/shield advances. At the same time, the cutterhead in the front part of the shield rotates and agitates the soil in the excavated face. The excavated material is then transported to ground surface through the slurry discharging pipe (for a slurry pressure balance (SPB) shield), or from the screw conveyor to the jacking pit via a trolley system (for an earth pressure balance (EPB) shield), and then lifted to ground surface. This procedure is repeated until the pipe string reaches the receiving pit. For manual excavation, the hand-shield and pipes behind are pushed forward progressively by the hydraulic jacking cylinders in the jacking pit when excavation of a certain length of ground is complete. The excavated material is then transported to the jacking pit for hoisting to ground surface via a trolley system. The size of a jacked pipeline could vary from $1,000 \mathrm{~mm}$ to $3,500 \mathrm{~mm}$.

Micro-tunnelling is pipejacking of small-sized pipelines using steerable remote-controlled mechanical tunnelling shields. The size of the shield ranges from $300 \mathrm{~mm}$ to $900 \mathrm{~mm}$ and is not suitable for man-entry.

The adoption of this technique, however, depends on whether there is space for construction of the jacking and receiving pits, the congestion of existing utilities at the pit locations, and other site constraints. It also requires a work site large enough for accommodation of the plant, equipment, and materials.

\section{Selection of design method and TBM, and operations}

TBM can operate in different ground conditions from soft ground to hard abrasive rock. A TBM is designed based on the expected geology. Selection of a TBM is a balance between geology and cost. If comprehensive geological information is available, this potentially can reduce the risk of a project and the cost of TBM and tunnelling. However, if geological information is insufficient, the TBM can be designed based on the worst case scenario, which means it will be more expensive, or else the work will be carried out with risk, which is unwise. 
Basically, there are two operating modes in TBMs, which are earth pressure balance (EPB) and slurry pressure balance (SPB), respectively. Their detailed particulars are given in the following sections.

\subsection{Earth pressure balance design}

Developed for use in silt and clay, the EPB system works on the principle of maintaining pressure in the excavation chamber equals to the hydrostatic pressure in the surrounding ground. This pressure is constantly monitored and controlled by varying the speed of the screw conveyor. The conveyor carries the excavated material from the excavation chamber through the bulkhead to the atmospheric pressure of the completed tunnel.

\subsection{Slurry pressure balance design}

Developed for working in unstable sand and gravel, this process employs high density bentonite slurry which is pumped into the excavation chamber, forming a cake over the excavation surface. This adds stability to the face and minimises the ingress of underground water. The excavated material is pumped out of the tunnel and the slurry is then separated in a processing plant for recycling use.

\subsection{Earth pressure balance TBM}

EPB TBM is limited to operating in soft ground or low rock strengths. At the working face, the excavated spoil falls downwards and is carried away by a screw conveyor with a mud hopper and a gate valve at the end. The gate valve maintains stable pressure to form a plug where the ground material is loose. The spoil is carried to the screw, which is mounted towards the outside to avoid plug formation. The screw conveyor is driven by means of a hydraulic aggregate. The earth balance is controlled by the material carried through the screw. The material is removed uniformly from the cutterhead area. The spoil is carried away by a continuous conveying belt. The cutterhead rotates either clockwise or anti-clockwise and changes its direction when the roll of TBM exceeds the tolerance. Conditioner in the form of foam or slurry is added to the excavated material in wet ground so that it becomes plastic to prevent water entering the screw conveyor during transportation. This conditioner will mix evenly with the excavated material during the rotation of the cutterhead. Bentonite-based lubricant or polymer in case of a clayey ground is injected to the annular space between the pipeline and the surrounding ground to reduce friction, through the automatic lubrication stations installed at suitable locations of the pipeline. For long drives, intermediate jacking stations are installed at suitable intervals of the pipeline, usually of not more than $80-100 \mathrm{~m}$, to ensure sufficient thrust for pushing the section of pipeline forward.

\subsection{Slurry pressure balance TBM}

SPB TBM is suitable for tunnelling through variable and alternating ground conditions made of soil and rock, and bedrock. Slurry is constantly injected into ground under pressure through the slurry pipe by charging pumps while the TBM advances. Excavated material mixed with slurry is filled in the excavation chamber behind the cutterhead, forming a cake to balance the soil and groundwater pressure ahead of excavation. It is then returned to the slurry

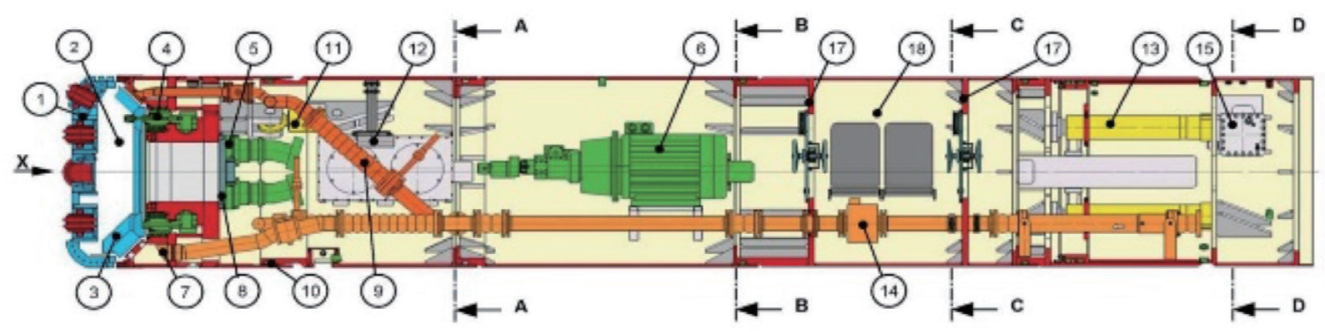

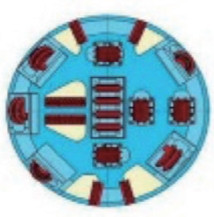

$\mathbf{x}$

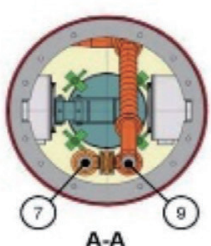

A-A

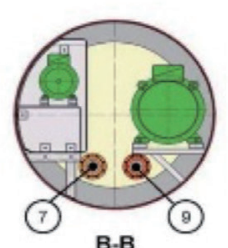

B-B

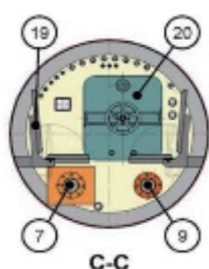

C-C

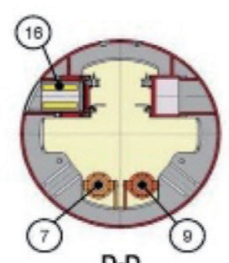

D-D
1 Cutting wheel 2 Excavation chamber 3 Crusher chamber 4 Main bearing 5 Gearbox assembly
11 Steering cylinder 6 Electric drive motor 7 Slurry discharge line 8 Face access hatch 9 Feed line 10 Articulation seal
12 ELS Laser target 13 Telescopic cylinder 14 Bypass assembly 15 Gripper assembly
16 Gripper cylinder 17 Airlock bulkhead 18 Airlock

19 Airlock seat 20 Airlock door

Figure 1. Typical configuration of a slurry-operated TBM (Herrenknecht, no date). 
treatment plant (desander) through the discharge pipe by discharge pumps. At the desander, the excavated material and slurry are separated. Only the slurry is recycled for use and the excavated material is disposed of off-site. The requirement of lubrication in the pipeline and intermediate jacking stations is same as that in the EPB TBM.

\subsection{TBM operating mechanism}

Depending on the design, pipejacking TBMs manufactured in Japan are generally operated by a number of driving motors, while those manufactured in Germany are operated by a hydraulic system. The main advantage of using driving motors is that if one motor malfunctions, the TBM can still be operated with a reduced efficiency. However, the motors occupy spaces in the TBM shield. The TBM operated by a hydraulic system has a higher driving capacity (more than double the power compared with electric-driven main drives) and the major system can be installed inside a container at ground level, but the TBM will stop if the system fails.

The design of the cutterhead in a SPB TBM can be tailor-made to suit the ground conditions likely to be encountered. A man access opening is provided in the front bulkhead of a TBM (for sizes of 1,500 mm or larger) to allow workers entrance to the excavation chamber for changing damaged disc cutters or removal of artificial obstructions. An airlock chamber can be equipped in a TBM with a size of $1,650 \mathrm{~mm}$ or larger and compressed air needs to be activated before opening of the man access. For driving in hard ground and at long length, a telescopic cylinder is required at the rear of the TBM to ensure sufficient thrust in cutting (Figure 1).

For EPB TBM, due to the large opening ratio in the cutterhead, the cutting tools are designed in the form of cutting teeth and scraping bits, and no replacement can be made in the course of excavation.

\subsection{Length of a pipeline constructed by TBM pipejacking and size of working pits}

Depending on the type, size, and configuration of the TBM, the size of a jacking pit and a receiving pit can be designed.

Slurry-operated TBMs manufactured by Herrenknecht have been commonly adopted in Hong Kong in recent years. These TBMs generally have two types of operating series: AVN and AVND. The difference is that in the AVND type, an air pressure regulating system is equipped to avoid blow-out or ground seepage at the tunnel face via an adjustable compressed air cushion. It is often called a mixshield or hydro shield.

Under the AVN type of TBM, there are numbers of series each with different characteristics. The drive length of the TB series (TBM with a man access door in the front bulkhead and with power pack) ranges from $500 \mathrm{~m}$ for a 1,200 $\mathrm{mm}$ diameter TBM to $900 \mathrm{~m}$ for an $1,800 \mathrm{~mm}$ diameter TBM, and the size of a jacking pit ranges from $4 \mathrm{~m}$ x $6 \mathrm{~m}$ for a $1,200 \mathrm{~mm}$ diameter TBM to $5 \mathrm{~m}$ x $8.5 \mathrm{~m}$ for an 1,800 mm diameter TBM. For the TC series (TBM with a man access door in the front bulkhead and hydraulic drive from a container on the ground to the TBM), the drive length is reduced to $250 \mathrm{~m}$ and $300 \mathrm{~m}$ for TBM diameters of 1,200 $\mathrm{mm}$ and 1,800 $\mathrm{mm}$, respectively (Herrenknecht TBM Catalogue, no date).

\subsection{Selection of pipeline alignment}

The horizontal alignment of a pipeline depends on the locations of jacking and receiving pits, which generally appears in a straight line.

At locations where the jacking/receiving pit or both are constrained by traffic, existing utilities and other issues, pit construction needs to be carried out in side streets, resulting in the need for a curved alignment.

The minimum radius for a curved alignment depends on the diameter and length of the jacking pipe, which governs the allowable angular deflection at the pipe joint. A straight transition length needs to be allowed between any two curves for smooth load transfer.

To properly control the alignment, the pipeline needs to sit in firm ground made of sandy material such as alluvium and completely decomposed granite (CDG). It is difficult to control the vertical and horizontal alignment of a pipeline passing through clayey material. Advanced grouting in the ground at and in the vicinity of the pipeline to strengthen the material is required before launching the TBM but its performance may not be efficient.

Apart from the size and shape of a jacking/receiving pit, utility crossings would govern the size of a TBM to be used and hence the pipe size. In some cases, several smaller diameter TBMs may have to be adopted to suit this constraint but due to the pit width being insufficient to allow aligning all pipelines at the same level, construction in two layers in the triangular, square, or trapezoidal shape would be required.

\subsection{Types of cutterhead in TBM and disc cutters}

The type and configuration of the cutterhead in a TBM is different in each project, which depends on the ground conditions (soft ground, mixed ground, and hard ground) likely to be encountered based on ground investigation results (Figure 2).

For soft ground, spoke or fan type of cutterhead with tungsten carbide cutting bits is used. For mixed ground, semi-dome type of cutterhead with steel alloy disc cutters and tungsten carbide cutting bits is deployed whereas for hard ground, dome type of cutterhead with disc cutters is used. Soft ground TBMs have a considerably more open structure in the cutterhead than hard ground TBMs to allow adhesive muck to pass through. Twin disc cutters save more 
space than single disc cutters. In addition, the cutting action of a twin disc is more effective in stabilization when cutting in boulders.

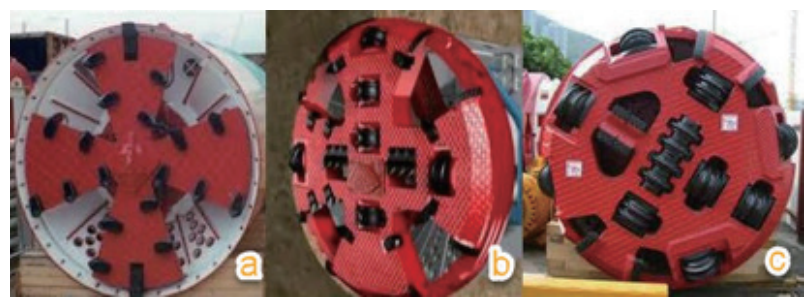

Figure 2. Configuration of cutterhead in TBM: (a) For soft ground; (b) For mixed ground; (c) For hard ground.

Disc cutters in a cutterhead are positioned in such manner that, during the excavation process, each disc cutter rotates in a designated circular path on the rock face ahead of the cutterhead while it is rotating. Vertical and radial cracks will form in the rock by the thrust exerted by the two adjacent disc cutters. Through the repeated rotation of the cutterhead and disc cutters, these cracks become larger and larger eventually leading to the rock in between loose out and become chips. They fall into the openings of the cutterhead for further reduction in size by the conical crusher behind before entering the spoil removal chamber.

The distance between the circular paths formed by disc cutters ranges from $50 \mathrm{~mm}$ to $100 \mathrm{~mm}$, depending on the positions of disc cutters in the cutterhead.

Gauge disc cutters are used to form the overcut between the TBM and the surrounding ground to allow passing-by of the TBM and pipeline behind. Gauge disc cutters and semi-gauge disc cutters have a higher frequency of replacement than center disc cutters due to the long travelling distance in each rotation of cutterhead.

Due to the irregular jutted profile of the cut face in rock, an overcut of about $50 \mathrm{~mm}$ would be required and it could be reduced to $30-40 \mathrm{~mm}$ in soil. The protrusion of the gauge disc cutters can be adjusted in the TBM to suit the ground conditions to be encountered.

Replacement of disc cutters is required during the TBM operation when the disc cutters are worn out exceeding their function limit or damaged. The life of a disc cutter depends on the strength and joints of the rock encountered. For hard and abrasive rock with uniaxial compressive strength greater than $250 \mathrm{MPa}$, replacement could be required in a drive length of every $8-10 \mathrm{~m}$. Change a disc cutter would require four to five hours based on those completed projects.

Activation of the compressed air is required to prevent ingress of groundwater before the man access opening in the bulkhead of the front shield of the TBM is opened to ensure the safety of working personnel. No compressed air work is necessary for replacement of disc cutters inside a rock pocket or bedrock if grout can be applied, from the
TBM, to seal off the annular space formed by the TBM to prevent ingress of water.

Whilst advancing in rock, small angular fragments of rock together with rock flour are prone to be displaced and build up in the annulus around the TBM/pipes. It is necessary to keep the annulus clean by keeping it full of bentonite slurry at all times during the jacking operation, particularly using the nozzles at the bottom of the TBM, to prevent the settling-out of these fragments and the formation of a wedge action on the pipeline, resulting in high jacking loads that would lead to pipe damage (Mok, 2006).

\subsection{Lubrication of jacked pipeline}

High-quality lubricating slurry is required to reduce skin friction and increase jacking distances, especially if the overcut is not adequate, as in the case of unstable soil. For long pipelines, a greater number of automatic lubrication systems, controlled by volume, must be installed and operated simultaneously for efficient lubrication of the pipeline during the jacking operation. A maximum of five systems can be operated in a TBM of 1,650 $\mathrm{mm}$ diameter or larger.

Lubricant injection starts next to the TBM to fill the annular space and then progressively in every fifth pipe in a downstream direction to maintain and keep up the lubrication film that has been established.

For long drives, injection needs to be carried out simultaneously at a number of locations on the pipeline to ensure that the annular space is filled up with lubricant at all times during the course of driving.

The influence zone of lubricant injection depends on ground conditions along the length of a pipeline and could vary significantly from $300 \mathrm{~mm}$ to 1 to $2 \mathrm{~m}$. In porous ground, lubricant could escape to the ground surface (Figures 3 and 4).

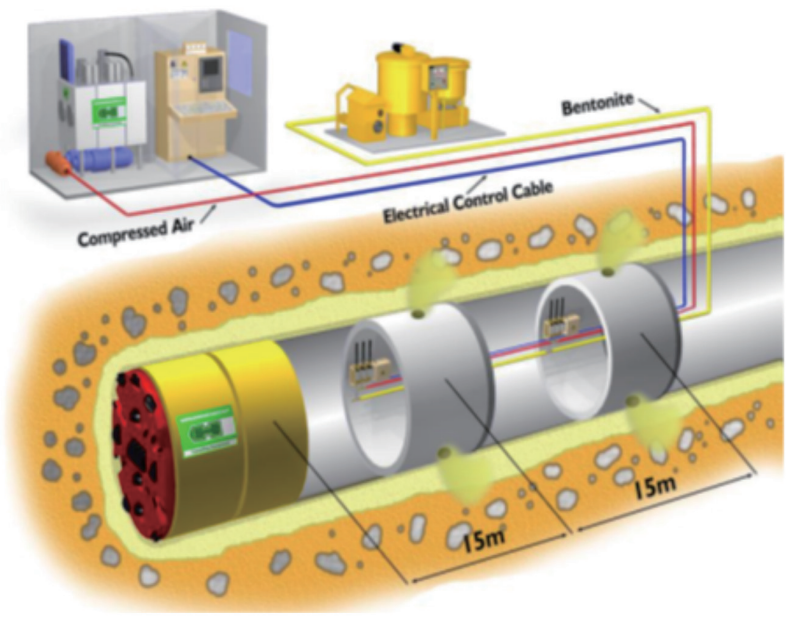

Figure 3. Typical arrangement of an automatic lubrication system in a pipeline (Herrenknecht, no date). 


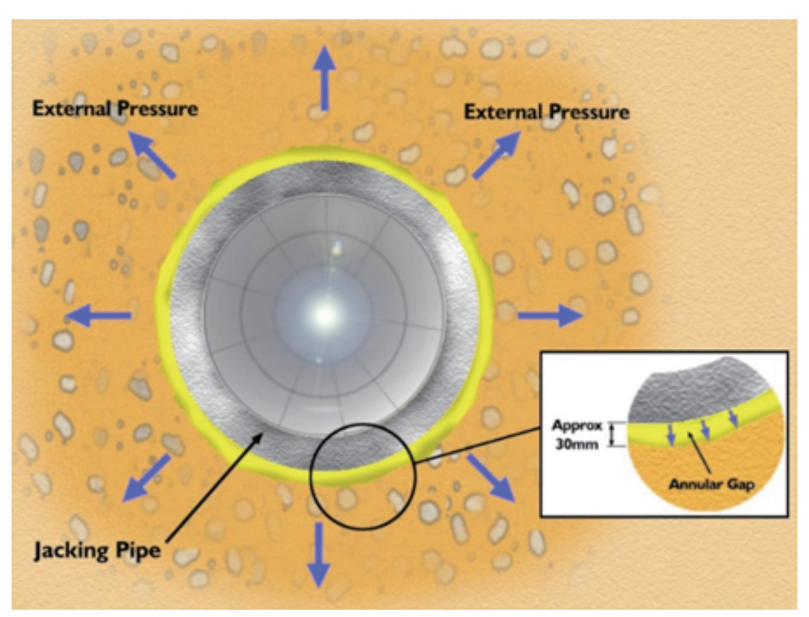

Figure 4. Effect of lubricant on surrounding ground (Herrenknecht, no date).

\subsection{Control of line and level of pipeline}

The tolerance for the vertical and horizontal alignment of a jacked pipeline is generally set at $50 \mathrm{~mm}$ and 75 $\mathrm{mm}$ respectively, as recommended by Specification for Tunnelling (The British Tunnelling Society and the Institution of Civil Engineers, 2000). For TBM pipejacking works, the tunnel is laser guided. The Electronic Laser System consists of a laser device installed at the rear of the jacking pit and an electronic target plate integrated with a two-axis inclinometer installed in the rear shield of the TBM. A laser beam transmitted from the laser device to the laser target measures the shield positions during the TBM advancement. It is applicable to all sizes of TBM with a drive length not exceeding $200 \mathrm{~m}$. In the event that the length is more than $200 \mathrm{~m}$, the system is supplemented with a hydrostatic water levelling system. The system is also capable of boring curved trajectories.

The Gyro Navigation System is required for straight drives exceeding $400 \mathrm{~m}$ in length and curved drives, but is unsuitable for a TBM smaller than $800 \mathrm{~mm}$ in diameter.

A special software records current shield positions based on rolling, pitching and yawing angles and calculates the nominal and correction curve for the continuing shield drive. The position of the TBM is displayed in the computer monitor located in the control room at ground level. The TBM operator can make the necessary adjustment to correct the position of the TBM by suitable combination of the extension and retraction of the steering jacking cylinders installed between the TBM's front and rear shields.

Correction of the alignment is done gradually to avoid abrupt change that might cause damage to the jacking pipes. To ensure the accuracy of the pipeline alignment, traditional control surveys will also be carried out at each drive length not exceeding $30 \mathrm{~m}$ (about five days' progress).

\subsection{Settlement monitoring}

TBM pipejacking works induce ground settlement. The deeper the tunnel, the smaller the ground settlement is and the wider the settlement influence zone, and vice versa. The acceptability of settlement magnitude depends on whether the stability of the adjacent roads, footways, utilities, and structures will be affected, and in general cases is less than $25 \mathrm{~mm}$. Although its magnitude is estimated based on ground investigation data with an assessment of its effect prior to commencement of the works, it is necessary to monitor the performance of such works by installing markers at suitable locations.

Normally, three rows of settlement markers are installed, with one along the centreline of the drive alignment and another two at offsets from that line at a suitable spacing, around 5 to $6 \mathrm{~m}$ depending on the diameter of the pipeline and the depth of overburden. Installation of the markers at $5 \mathrm{~m}$ intervals in each row is the usual practice. Some of the marker locations may need to be changed to suit site conditions. Nail marker installation is only good for flexible pavements and can always provide reasonably accurate readings. In addition, ground settlement under this type of pavement can be easily detected by visual inspections on the cracks developing therein. For pipejacking works below rigid pavements, experience has shown that sub-surface markers in the form of a mild steel rod with base plate should be used as the pavement itself can withhold by its rigidity for some time even though the soil underneath has settled. These markers require coring of holes through the concrete slab, and a PVC tube inserted to encase the steel rod. Its depth should be limited to not more than $600 \mathrm{~mm}$ below the slab to avoid possible damage to the utilities and services laid in the ground. The holes are then filled with sandy materials to maintain the verticality of the steel rods, and steel caps are provided to prevent ingress of surface runoff which would affect the accuracy of the readings. Upon completion of the works, the steel rods are removed and the holes in the concrete slab are properly reinstated.

When settlement is detected on the ground surface, its influence zone will be in the range of 45 degrees to 60 degrees projected from the face and rear of the TBM in the longitudinal direction and from its two sides in the transverse direction. All existing utilities and structures falling within this zone are subject to a stability check. Depending on ground conditions, the respective settlement could take a few days to a few weeks to complete. Hence, it is essential to continue monitoring for some time after completion of the work so that an overall picture on ground settlement can be obtained before reinstatement of the permanent road (Mok and Mak, 2009). 


\section{Development of pipejacking techniques adopted for pipeline construction in Hong Kong}

The history of using pipejacking techniques has been short to date. The first Government project using these techniques with a track record was the Fanling Trunk Sewer project for the Territory Development Department (TDD) of the Hong Kong Government, in mid-1989. A 370-metrelong sewer of 1,350 mm diameter located at $6-14 \mathrm{~m}$ below ground level was constructed beneath new roads, footpaths, a cycle track, a pedestrian subway, the embankment of the Fanling Bypass and many existing utilities. The project used an Unclemole EPB TBM manufactured by Iseki, and the work was completed in about six weeks with an average production rate of $10 \mathrm{~m}$ per day.

Since 1991, more than 30 kilometre-long pipelines using different pipejacking/micro-tunnelling techniques have been completed by the Drainage Services Department (DSD) of the HKSAR Government, under different ground conditions, in projects of different scales.

Before 1996, the total length of most of the pipelines constructed in a project was generally less than $1 \mathrm{~km}$, and one even had a length of only $50 \mathrm{~m}$ for crossing the road junction. These pipelines generally had a depth range of $3-10 \mathrm{~m}$, with an average of $5 \mathrm{~m}$. A typical example was the construction of twin 2,800 $\mathrm{mm}$ diameter pipelines in Mongkok Road, crossing the junction of Tong Mei Road by an EPB TBM manufactured by Komatsu in the West Kowloon Reclamation Hinterland Drainage Package 2 (Northern Portion) Project under TDD.

Between 1991 and 1996, Iseki's Unclemole EPB TBM was widely adopted. This type of TBM generally performed satisfactorily in homogeneous ground (made of sand and clay) but had difficulty cutting through big boulders, resulting in the necessity of a rescue pit in some cases.

Starting from 1996 onwards, more projects used pipejacking, with different types of TBMs and in different modes, to account for the ground conditions likely to be encountered, for pipeline construction in a large scale, with the length of pipeline increased to a few kilometers and the depth increased to $20-25 \mathrm{~m}$. It was also at this time that hand-dug tunnels were first used for constructing pipelines crossing old seawalls and artificial obstructions. Some of the most notable projects, like the Central, Western and Wan Chai West Trunk Sewers, the Aberdeen, Ap Lei Chau and Pok Fu Lam Sewerage - Stage 1B and Wan Chai East $\&$ North Point Sewerage - Trunk Sewers, were carried out between 1996 and 2005 using different trenchless techniques. SPB TBMs manufactured by Herrenknecht AG and RASA Industries Ltd., respectively, started to become popular for different ground conditions in late 1990s (Mok and Mak, 2009). EPB TBMs are seldom used in the 2020s, except for shallow drives. The use of SPB TBMs manufactured in China is also noticeable in some projects.

The Wan Chai East \& North Point Sewerage - Trunk Sewers was the first DSD project using the pipejacking method of slurry-operated TBMs to construct curved sewers, with a diameter of $1,800 \mathrm{~mm}$ and minimum radius of $320 \mathrm{~m}$, and an S-shape sewer (404 m long), with a combination of a straight and two curved sections (minimum radius of 500 $\mathrm{m}$ ) passing through an intermediate pit and launching into the receiving pit, both with the completion of the permanent shaft structure in advance. This project commenced in May 2002 and was completed in December 2005 (Mok et al., 2007a; Mok et al., 2007b). Other noticeable completed DSD projects were the construction of a 162-metre-long curved pipeline of $1,200 \mathrm{~mm}$ diameter, with a minimum radius of $200 \mathrm{~m}$, in Tai Po, and a 516-metre-long double curve pipeline of $1,200 \mathrm{~mm}$ diameter, with a minimum radius of $452 \mathrm{~m}$ and $337 \mathrm{~m}$, respectively, in Bonham Strand in 2007, which is currently the longest curved drainage pipeline.

A number of different innovative construction techniques were introduced to the Kai Tak Cooling System Phase IIIA Project, under the Electrical and Mechanical Services Department (EMSD) of HKSAR during the period from 2012 to 2017 (Mok et al., 2018; Mok et al., 2019). These include: enlargement in the lower portion of a receiving pit for receiving the TBM and then dismantling the TBM shields after completion of the pipejacking; construction of a hand-dug tunnel from the receiving pit to receive three TBM due to shifting of the original pit location and size constraints due to congested utilities; construction of twin pipelines, each 2,800 $\mathrm{mm}$ in diameter and $350 \mathrm{~m}$ in length, $10 \mathrm{~m}$ below the seabed across the Kai Tak Approach Channel (a first in Hong Kong); parallel running of two $1,500 \mathrm{~mm}$ diameter TBM to speed up the progress; and skinning of the TBM body for lifting to ground surface due to the limited size of the receiving pit.

At the time of its construction, the longest single drive completed in Hong Kong was 650 m in DSD's Rising Main Project in Tung Chung, using a 1,650 mm diameter slurryoperated TBM, in a ground made up of soil, soil mixed with boulders and bedrock along the TBM alignment. This drive was completed in 2018.

The largest TBM adopted in a project was the construction of 57 cross passages of $3,000 \mathrm{~mm}$ diameter, each with a length ranging from $1.5-13 \mathrm{~m}$, at a spacing of $100 \mathrm{~m}$ between the two main tunnels, using a slurryoperated TBM in the Tuen Mun Chap Lap Kok Link Project in the late 2010s.

The technique in which the TBM is retracted from the end of a completed pipeline to the jacking pit, due to insufficient receiving pit size as constrained by existing utilities or no room for construction, has been adopted in recent projects. It requires detaching its inner ring from its outer ring and folding the cutterhead or losing its outer part during the retraction operation. Typical applications are drainage works and pipe arch construction. It has also been applied to construct sleeve pipelines in advance through boulder or unstable ground so that the alignment of horizontal directional drilling (HDD) can be maintained. 
Rectangular TBM technique, using the EPB operating mode and precast concrete segments as tunnel lining, was introduced to construct a pedestrian subway across Prince Edward Road East in June 2020.

The summary of TBM pipejacking works completed in major projects is given in Table 1 .

\section{TBM pipejacking - types of technique to deal with different site constraints and ground conditions}

Apart from the traditional construction of a pipeline from a jacking pit to a receiving pit, innovative TBM pipejacking techniques have been developed and adopted in the projects highlighted in the section "Development of pipejacking techniques adopted for pipeline construction in Hong Kong", with success, to suit various site constraints, and ground conditions experienced. Such techniques include:

\subsection{Curved pipeline}

Traditional pipejacking alignment appears in a straight line. There are, however, situations in which this cannot be done due to utility constraints limiting the locations of jacking and receiving pits, or other constraints like the footbridge foundation preventing the pipeline alignment in between the two pits. Development of TBM technology allows the pipeline alignment to run in a curved profile by suitably using the steering jacking cylinders installed in the TBM. The minimum radius of a jacked pipeline depends on the pipe size and length, ranging from $190 \mathrm{~m}$ for onemetre-long pipe to $570 \mathrm{~m}$ for three-metre-long pipe, for an allowable angular deflection at the pipe joint of 0.3 degrees. This corresponds to a $2,500 \mathrm{~mm}$ diameter pipeline. It changes to $115 \mathrm{~m}$ and $340 \mathrm{~m}$, respectively, for an allowable angular deflection at the pipe joint of 0.5 degrees for a $1,500 \mathrm{~mm}$ diameter pipeline. This technique is capable of constructing a pipeline in more than one curve to suit the needs required by the minimum radius, with a smooth

Table 1. Summary of TBM pipejacking works completed in major projects in Hong Kong.

\begin{tabular}{|c|c|c|c|c|c|}
\hline Year & Project & $\begin{array}{l}\text { Tunnel size } \\
(\mathrm{mm})\end{array}$ & \begin{tabular}{c|} 
Length and \\
depth of tunnel (m)
\end{tabular} & Type of TBM & Ground conditions \\
\hline 1993 & $\begin{array}{l}\text { West Kowloon } \\
\text { Reclamation } \\
\text { Stormwater } \\
\text { System }\end{array}$ & 1,650 and 2,600 & $\begin{array}{l}\text { Length: } 40-100 \\
\text { straight } \\
\text { Depth: } 5-8\end{array}$ & EPB & Alluvium \\
\hline 1996 & $\begin{array}{l}\text { Central, Western } \\
\text { and Wanchai West } \\
\text { Trunk Sewer }\end{array}$ & 1,200 and 1,800 & $\begin{array}{l}\text { Length: } 53-210 \\
\text { straight } \\
\text { Depth: } 6-15\end{array}$ & SPB & Alluvium, CDG \\
\hline 2000 & $\begin{array}{l}\text { Aberdeen, Po Fu } \\
\text { Lam and Ap Lei } \\
\text { Chau Trunk Sewer }\end{array}$ & 1,500 & $\begin{array}{l}\text { Length: } 80-120 \\
\text { straight } \\
\text { Depth: } 8-10\end{array}$ & SPB & $\begin{array}{l}\text { Alluvium, CDG, } \\
\mathrm{M} / \mathrm{SWG}\end{array}$ \\
\hline 2003 & $\begin{array}{l}\text { Wanchai East and } \\
\text { North Point Trunk } \\
\text { Sewer }\end{array}$ & $\begin{array}{l}600,1,200 \text { and } \\
1,800\end{array}$ & $\begin{array}{l}\text { Length: } 40-404 \\
\text { straight and curved } \\
\text { Depth: } 6-18\end{array}$ & SPB & $\begin{array}{l}\text { Alluvium, CDG, } \\
\mathrm{M} / \mathrm{SDG}\end{array}$ \\
\hline 2012 & $\begin{array}{l}\text { Kai Tak District } \\
\text { Cooling System } \\
\text { Phase IIIA }\end{array}$ & $\begin{array}{l}1,200,1,500 \text { and } \\
2,800\end{array}$ & $\begin{array}{l}\text { Length: } 32-350 \\
\text { straight } \\
\text { Depth: } 6-25\end{array}$ & SPB & $\begin{array}{l}\text { Alluvium and } \\
\text { CDG }\end{array}$ \\
\hline 2018 & $\begin{array}{l}\text { Tung Chung } \\
\text { Rising Main }\end{array}$ & 1,650 & $\begin{array}{l}\text { Length: } 650 \\
\text { straight } \\
\text { Depth: } 5.6-16\end{array}$ & SPB & $\mathrm{CDG}$ and $\mathrm{M} / \mathrm{SDG}$ \\
\hline 2019 & $\begin{array}{l}\text { Airport Authority } \\
\text { Pipe Roof } \\
\text { Construction }\end{array}$ & 26 nos. 1,200 & $\begin{array}{l}\text { Length: } 27 \text { each } \\
\text { Depth: } 6\end{array}$ & SPB & $\begin{array}{l}\text { Fill treated with } \\
\text { Grout }\end{array}$ \\
\hline 2020 & $\begin{array}{l}\text { Kai Tak Pedestrian } \\
\text { Tunnel }\end{array}$ & $3,900 \times 2,800$ & $\begin{array}{l}\text { Length: } 140 \\
\text { Depth: } 8-9\end{array}$ & EPB RTBM & $\begin{array}{l}\text { Fill/Alluvium/ } \\
\text { CDG }\end{array}$ \\
\hline \multicolumn{3}{|c|}{$\begin{array}{l}\text { Legend: } \\
\text { CDG - Completely Decomposed Granite } \\
\text { M/SDG - Moderately to Slightly Decomposed Granite }\end{array}$} & \multicolumn{3}{|c|}{$\begin{array}{l}\text { RTBM - Rectangular Tunnel Boring Machine } \\
\text { EPB - Earth Pressure Balance } \\
\text { SPB - Slurry Pressure Balance }\end{array}$} \\
\hline
\end{tabular}


transition length of $10-12 \mathrm{~m}$ in between. This would generally resolve the problem of jacking and receiving pit locations due to site constraint (Mok, 2006; Mok et al., 2007a; Mok et al., 2007b).

This technique has been adopted in various DSD projects with TBM diameters of 1,200-1,800 mm under different ground conditions from Fill to $\mathrm{CDG}$, and the performance was satisfactory in terms of daily output, excavation, alignment control and settlement (Figures 5-7).

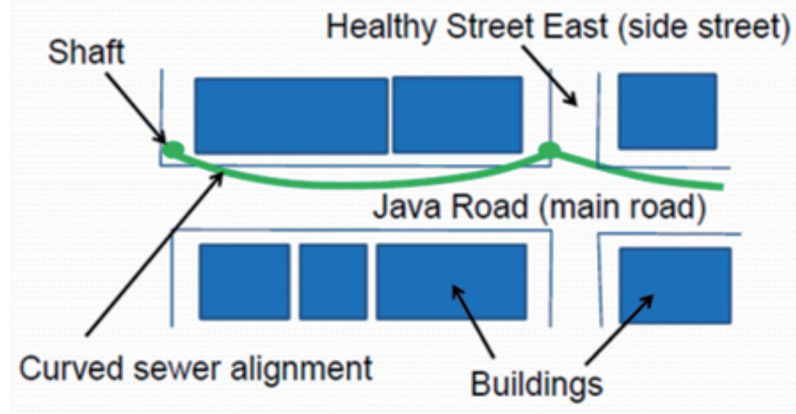

Figure 5. Single curve in a jacked pipeline.

\subsection{Length of pipeline in a single drive}

The length of a pipejacking drive is generally limited in the range of $100-200 \mathrm{~m}$. Developments in TBM technology have allowed for the increase in the length of a pipeline to $500 \mathrm{~m}$ for $1,200 \mathrm{~mm}$ diameter TBM and $900 \mathrm{~m}$ for TBMs with a diameter larger than 1,650 mm (Herrenknecht AG, no date), by operating more intermediate jacking stations and installing two or more volume-controlled automatic lubrication systems in the pipeline. These lubrication systems are activated simultaneously, with the first one covering the first length from the rear of TBM and others covering the remaining lengths towards the jacking pit.

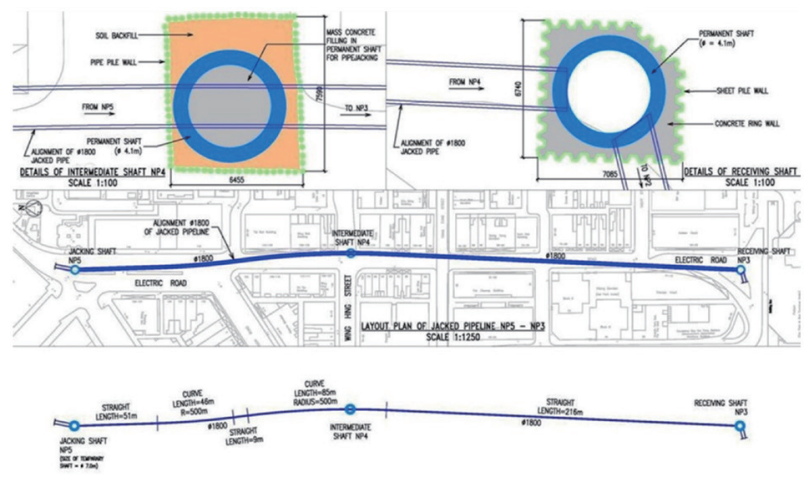

Figure 6. Double curve in a jacked pipeline passing through an intermediate pit with permanent concrete chamber.

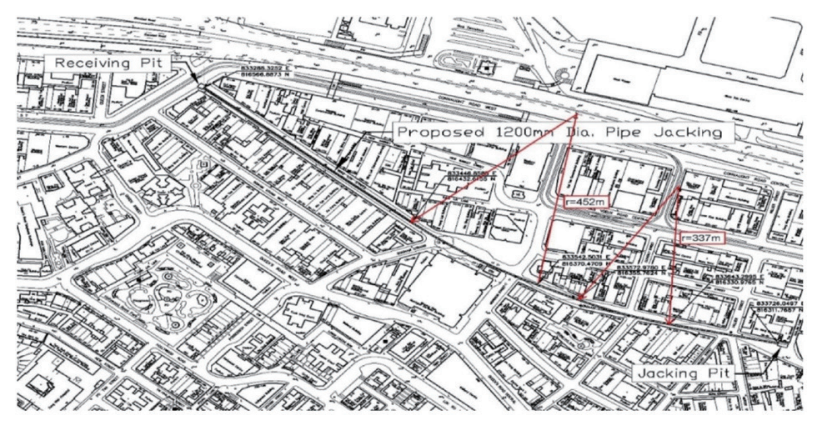

Figure 7. Longest double curve drainage pipeline: 516 $\mathrm{m}$ long with minimum radius of $452 \mathrm{~m}$ and $337 \mathrm{~m}$, respectively (courtesy of VTEC).

This would ensure smooth running in a long drive with sufficient thrust to push the pipeline forward, eliminating the friction force developed on the pipeline if one lubrication system is adopted as normally faced (Figures 8 and 9).

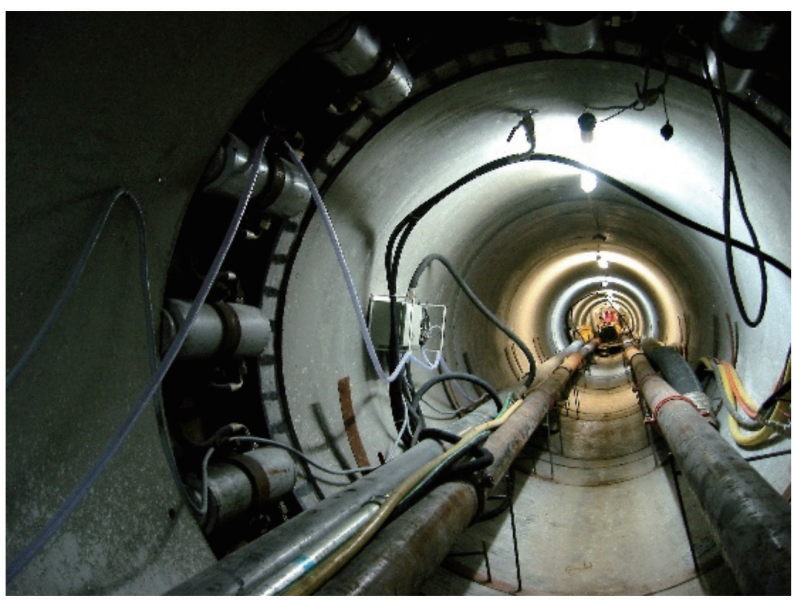

Figure 8. Appearance of a jacked tunnel with intermediate jacking station and automatic lubrication system.

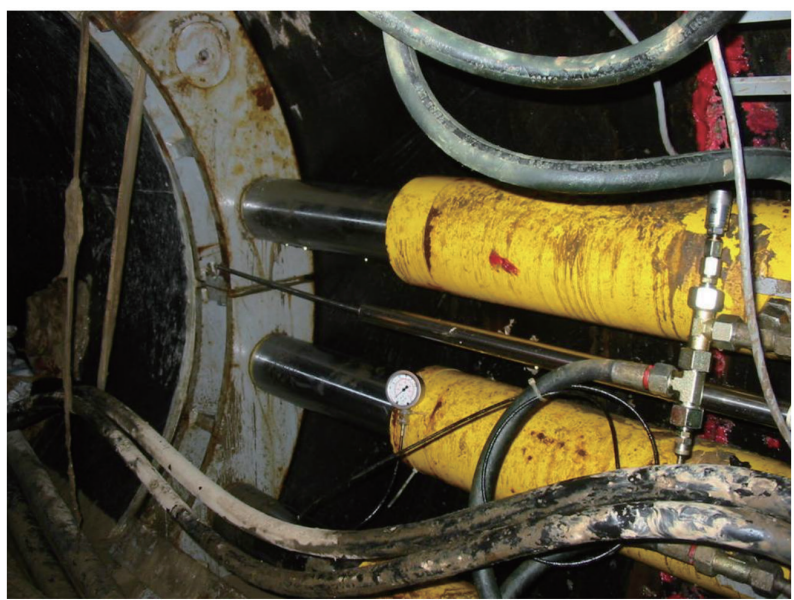

Figure 9. Operation of hydraulic jacks in an intermediate jacking station. 


\subsection{Pipeline passing through raking piles supporting structures}

For a TBM pipeline passing through groups of raking piles supporting structures like flyovers and box culverts, it is necessary to control its vertical and horizontal alignment. To ensure proper and safe construction, a geophysical survey such as radar method, vector magnetic method, sonic probing method, etc., should be carried out in advance with the aim of determining the true as-built geometries of the piles, such that the jacked pipeline can be constructed with confidence and minimum risk. A DSD project at Wan Chai had successfully completed a pipeline of $1,800 \mathrm{~mm}$ diameter, crossing the raking pile groups supporting the Canal Road Flyover with a minimum clearance of $0.45 \mathrm{~m}$ at the nearest pile (Cosine Ltd., 2001).

\subsection{TBM passing through intermediate pits for long drives}

The benefit of using this method is the flexibility of programming which can make the re-sequencing of works easier should site problems be encountered. In addition, there will be a cost saving in not moving and setting-up the TBM plant at the intermediate pit locations.

This requires construction of the receiving and launching eyes at the sheet-piles of the intermediate pit before the jacked pipeline passes through. The condition of the TBM can be inspected in the pit and the damaged disc cutters, if any, changed before the pipeline is pushed forward further.

To avoid groundwater drawdown which could lead to ground settlement, the pit should be flooded with water to balance the groundwater pressure inside and outside. A double-layer rubber seal is installed at both eyes to minimise the loss of lubricant and migration of the fines in the surrounding ground when the jacking continues. A steel or wooden planking system is provided on top of the pipeline to prevent floatation. Alternatively, the intermediate pit could be temporarily backfilled for the intended purpose.

An example was the construction of an 1,800 $\mathrm{mm}$ diameter pipeline, $300 \mathrm{~m}$ long, passing through two intermediate pits in Western District in a DSD project (Mok and Mak, 2009).

\subsection{With completion of permanent chambers in intermediate pits and receiving pit in advance}

To meet the tight schedule of works, it is sometimes required to construct the permanent chamber structure in the intermediate pit(s) or the receiving pit in parallel to the jacking operation. As illustrated by a DSD project in North Point (Mok et al., 2007a; Mok et al., 2007b), the permanent reinforced concrete chamber was completed first, with the receiving and launching openings prefixed and formed. A mass concrete fill was then provided across the chamber to confine the alignment of the jacked pipeline and prevent the escape of lubricant when the pipeline was passing through. This enabled inspection of the condition of the disc cutters and their necessary replacement.

The gap between the temporary pit and the permanent chamber at the "opening" locations was sealed up by concrete to prevent ingress of water causing drawdown outside the working pit and attracting unnecessary ground settlement.

The speed of the 1,800 mm diameter TBM, when approaching close to the temporary pit, was reduced and the position of the TBM was double-checked and adjusted, before the TBM was pushed in. The jacking force and speed of driving was controlled so that the vibration induced did not damage the permanent chamber.

Upon completion of the pipejacking works, the gap between the permanent chamber wall and the pipeline was properly sealed up by non-shrinkage epoxy grout.

For the receiving pit, the internal size of the permanent circular chamber was just enough to allow removal of the longest section of the TBM with a clearance of $100 \mathrm{~mm}$ in the course of lifting, and the internal fixtures and top slab of the chamber were completed afterwards.

\subsection{Pipeline passing through a narrow gap with road/ utilities on top and box culvert and the like at bottom in Causeway Bay}

In a DSD project, a 1,200 $\mathrm{mm}$ diameter TBM pipeline passed through a gap with $600 \mathrm{~mm}$ and 1,000 $\mathrm{mm}$ clearance with congested overlying utilities and an underlying pedestrian subway below Hennessy Road, respectively. Its alignment was properly controlled by a laser-guided system, and the jacking speed and jacking load was closely monitored when the TBM was approaching. The pipeline was successfully completed with the alignment maintained within +/-10 mm (Mok et al., 2007a; Mok et al., 2007b).

\section{Some observations}

(1) The advancement of TBM technology has allowed pipelines to be executed in a single drive with a length up to $1,000 \mathrm{~m}$, without the need of intermediate pits. This would enable solving the problems associated with working pit locations, and for construction of long outfall pipelines, due to site constraints.

(2) To ensure success, a TBM with suitable configuration should be selected based on site constraints and ground conditions likely to be encountered. Improper selection of TBM could result in the TBM getting stuck in ground, requiring a rescue operation by a rescue pit if traffic permits and there are no overlying utilities. Otherwise, a rescue tunnel would be required, which is risky, time-consuming and expensive. 
(3) Due to the congested network of existing utilities, which generally occupies most of the locations at shallow ground, new pipelines are constructed deeper and deeper. The use of EPB TBMs is difficult as their configuration may not be compatible to the ground conditions encountered. This probably explains why slurry-operated TBMs are more commonly used in recent years.

(4) A jacked pipeline passing through a completed permanent concrete chamber in an intermediate pit, with pre-fixed openings in the structure, has proved to be viable to speed up progress, particularly at pit locations where public complaints about lengthy occupation of the works area causing loss of business and affecting the environment are a major concern. It would also reduce disruption to traffic. By allowing construction of the permanent chamber immediately after completion of the intermediate pit, reinstatement of the occupied area (except for the receiving pit location where the top slab of the permanent chamber is to be placed after the retrieval of the TBM) and release of the site to the public can be made at a much earlier stage. There is no restriction on the number of intermediate pits that the TBM and pipeline can pass through.

(5) The efficiency of TBM driving can be ensured if lubricant is applied through sufficient automatic lubrication stations installed in the pipeline and operated by sufficient lubrication systems at the same time in the driving.

\section{Conclusion}

(1) Rapid TBM development enables long drives in variable and alternating ground conditions, eliminating problems associated with finding locations for construction of jacking and receiving pits due to utilities and other constraints.

(2) Laser-guided systems give confidence as to the control of tunnel alignment, particularly passing through already-constructed permanent structures, and in multi-curves.

(3) Selection of design method and TBM must be exercised with care to avoid TBM stoppage.

\section{Acknowledgments}

The authors wish to express their gratitude to Victory Trenchless Engineering Company Limited (VTEC) for providing some of the technical data and photographs from the respective projects for this paper. Special acknowledgement is given to Herrenknecht AG for permission to extract relevant information and photographs from technical brochures in making this paper.

\section{Notes on contributors}

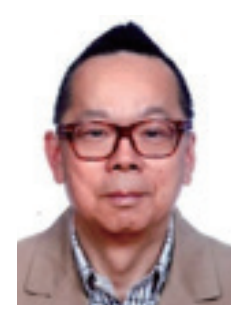

Ir Wilson W S Mok graduated from the University of Windsor in Canada and has over 42 years of practical working experience in a wide variety of geotechnical and civil engineering projects in both design office and site. $\mathrm{He}$ is a chartered civil and geotechnical engineer. He is also a Fellow of The Hong Kong Institution of Engineers, the Institution of Civil Engineers, and the Chartered Institution of Civil Engineering Surveyor. He specialises in geotechnical investigations and instrumentation, deep excavations, pipejacking, tunnels, ground improvements, settlement analysis, reclamation, site formation, slope preventive measures, foundations and sewerage works. He has been involved in the design, construction supervision and administration of more than 24 kilometre-long pipeline construction projects in the urban areas of Hong Kong, using different types of trenchless techniques. He is the author/co-author of several technical papers in this aspect, and his paper titled "Sewer installation by pipejacking in the urban areas of Hong Kong", in two parts, has been awarded the HKIE Transactions Prize 2007. His paper "Challenges in Construction of the Phase IIIA District Cooling System in Kai Tak" received the Overall Best Award from ACEHK in 2017 . He is currently an independent consultant for trenchless works.

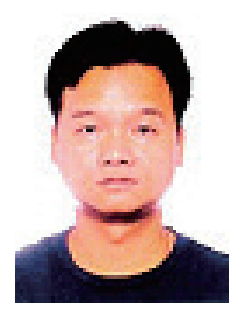

Ir Andrew S W Ng graduated from Coventry University in the United Kingdom in 1992. He has over 25 years of construction experience in a wide range of civil engineering projects including road, water and drainage works, and pipe works for tunnel support. He is a chartered engineer, with membership in The Hong Kong Institution of Engineers and the Institution of Mechanical Engineers. He has been involved in trenchless construction works for various drainage and utilities installations by tunnel boring machines and other techniques for projects in government and the private sector since 1996. He is the founder of Victory Trenchless Engineering Co., Ltd., which provides solutions to construction projects of using different trenchless techniques.

\section{References}

[1] Cosine Ltd. (2001). Final Report on Geophysical Investigations of Raked Piles, Canal Road, Wan Chai.

[2] Herrenknecht AG (no date). Herrenknecht TBM Catalogue in Utility Tunnelling. 
[3] Mok W W S (2006). Straight or Curved Sewers? Pipejacking Options in Hong Kong. In: HKIE GDC Annual Seminar.

[4] Mok W W S, Mak M K W and Poon F HT (2007). Sewer Installation by Pipejacking in the Urban Area of Hong Kong: Part I - Planning, Design, Construction and Challenges. HKIE Transactions, 14(1), pp. 17-30.

[5] Mok W W S, Mak M K W and Poon, F H T (2007). Sewer Installation by Pipejacking in the Urban Area of Hong Kong: Part II - Performance of Works, Lessons Learned and Improvements Proposed, HKIE Transactions, 14(1), pp. 31-43.

[6] Mok, W W S (2007). Pipejacked Tunnels - What to do If a Tunnel Boring Machine is Stuck in Ground?. Trenchless Conference in Macau. Macau.

[7] Mok W W S, Mak K W (2009). Tunnelling and Pipejacking Techniques for Trenchless Installation of Drainage Pipelines, HKIE Transactions, 16(2), pp. 1-12.

[8] Mok W W S, Lo V K Y and Chau G T M (2016). Trenchless Construction for District Cooling System (DCS) in a Smart City: A Case Study on Kai Tak Development in Hong Kong. In: Trenchless Conference in Hong Kong. Hong Kong.

[9] Mok W W S (2017). Challenges in Construction of the Phase IIIA District Cooling System in Kai Tak. In: Association of Consulting Engineers Hong Kong (ACEHK) Annual Award 2017.

[10] Mok W W S, Lo V K Y, Chau G T M, Lau L Y M (2018). Trenchless Construction of Phase IIIA District Cooling System (DCS) by TBM Pipejacking and Hand-dug Tunnelling on Kai Tak Development: Part I - Design and Construction Considerations, HKIE Transactions, 25(1), pp. 56-66.

[11] Mok W W S, Lo V K Y, Chau G T M, Lau L Y M (2019). Trenchless Construction of Phase IIIA District Cooling System (DCS) by TBM Pipejacking and Hand-dug Tunnelling on Kai Tak Development: Part II - The Challenges. HKIE Transactions, 26(1), pp.2029.

[12] Mok W W S (2019). Innovative Pipe Installation by Trenchless Construction. In: CIC Competition 2019. Construction Industry Council.

[13] O'Reilly M P and New B M (1982). Settlement above Tunnels in the United Kingdom - Their magnitude and Prediction. In: Proceedings Tunnelling' 82 Symposium. United Kingdom: Institute of Mining and Metallurgy.

[14] Pipe Jacking Association, (1995). Guide to Best Practice for the Installation of Pipe Jacks and Microtunnels. United Kingdom, pp.24, 44-56.

[15] The British Tunnelling Society and the Institution of Civil Engineers, (2000). Specification for Tunnelling, United Kingdom: Thomas Telford, pp. 36, 86-88 \& 106.
[16] Thomson J (1993). Pipejacking and Microtunnelling, United Kingdom: Black A\&P. 